\title{
KOSTENCALCULATIES, WAARDERINGSSTELSELS EN BESLUITVORMING*
}

\author{
door Drs. W. A. Nijenhuis
}

\section{Par. 1 Inleiding}

In het schrijven van beschouwingen over waarderingssystemen en calculatiemethoden zijn velen mij reeds voorgegaan. Het gezichtspunt, van waaruit men de waardering en calculatie beschouwt, met andere woorden het doel waarvoor de berekeningen en waardebepalingen worden (geacht te zijn of te worden) uitgevoerd, bepalen in belangrijke mate de inhoud en strekking van verhandelingen over deze onderwerpen. Een duidelijk voorbeeld hiervan zien we als we vergelijken het praeadvies van Burgert voor de accountantsdag van 1967, de bijdrage in de discussie van de middagvergadering van Bouma en het artikel van Van Kampen in het aprilnummer van het M.A.B.' ').

Zowel Burgert als Bouma gaan uit van de gedachte dat de jaarrekening een middel is tot communicatie en derhalve tot taak heeft informatie te verstrekken. Beide auteurs geven verder als hun mening te kennen, dat meerdere doelstellingen van de onderneming mogelijk zijn. Ter beoordeling van het gevoerde beleid is het noodzakelijk, dat de gehanteerde begrippen en grootheden op elkaar zijn afgestemd, hetgeen wil zeggen, dat er afstemming moet plaats vinden tussen de informatievariabelen en de doelvariabelen. In deze gedachtengang staan balanswaardering en winstbepaling niet los van de doelstelling van de onderneming.

Van Kampen daarentegen spreekt zich uit tegen deze nieuwlichterij, als zou de bedrijfseconomische betekenis van de jaarrekening gelegen zijn in de informatieverstrekkende functie. „Het is noodzakelijk de woorden bedrijfseconomische of economische functie te reserveren voor de functie, welke de continuiteit van de onderneming dient"' $)$. Weliswaar spreekt Van Kampen over de informatieve functie van de balans, maar deze wordt door hem als een secundaire aangelegenheid betiteld en krijgt bij de bespreking ook veel minder aandacht dan de ,vermogensbewakende" functie, die bij hem centraal staat.

Deze verschillen in benaderingswijze wat betreft de functie van de jaarrekening en met name van de balans resulteren in totaal verschillende beschouwingen en uitspraken. Van Kampen betreurt het, dat de meningen steeds verder uiteenlopen en dat er van het ontdekken van de waarheid op dit terrein zo weinig terechtkomt.

Op zichzelf is het mijns inziens geenszins beangstigend en in strijd met de

* De schrijuer is veel dank verschuldigd aan prof. dr. J. L. Bouma voor het kritisch doorlezen van een eerder concept van dit artikel en het doen van een aantal waardevolle suggesties tot verbetering.

1) R. Burgert, bedrijfseconomisch aanvaardbare grondslagen voor de gepubliceerde jaarrekening, Praeadvies voor de Accountantsdag 1967, Bijlage bij ,de Accountant" no. 4 (september 1967), p. 153-192; Verslag 50e Accountantsdag, 4 november 1967, de Accountant, febr. 1968, p. 503-510; L. van Kampen Jr., De functie van de balans, Maandblad voor Accountancy en Bedrijfshuishoudkunde, april 1969 , p. $156-175$.

2) Van Kampen, t.a.p. p. 159.

ma $b$ blz. 469 
wetenschapsbeoefening, dat men onder verschillende vooronderstellingen en uitgangspunten tot afwijkende (ieder voor zich logisch beredeneerde) conclusies komt. Waar het ondermeer om gaat is of de geformuleerde theorieën enig praktisch nut hebben; wat de bedrijfseconomische theorieën betreft, of zij van nut kunnen zijn voor de verklaring en voorspelling van het ondernemingsgedrag en een bijdrage kunnen leveren voor een beleidsvoering, die zo goed mogelijk beantwoordt aan de gestelde doeleinden. Wanneer Van Kampen van mening is, dat de balans als functie heeft om het beklemde vermogen (dit is het vermogen, dat onder de klem van de vervanging ligt ${ }^{3}$ ) weer te geven, is hier a priori niets tegen. Wel mag worden verwacht dat een balans, hoe dan ook opgesteld, enige informatieve betekenis heeft. Wat zou het voor zin hebben om het beklemde vermogen te berekenen, als hierbij niet voorop stond op grond van de aan een dergelijk gegeven te ontlenen informatie een beslissing om te handelen te nemen. Het berekenen van uitkomsten, waarmee men niets kan doen, kan beter achterwege worden gelaten. Het punt waar het om draait is of aan de verkregen gegevens de gewenste, benodigde informatie kan worden ontleend. Zodra de mogelijkheid wordt onderkend, dat er meerdere groepen zijn, die behoefte hebben aan (verschillende) informatie of dat een bepaalde groep of individu behoefte heeft aan verschillende informatie, afhankelijk van het nagestreefde doel en de te nemen beslissing, wordt het des te moeilijker zo niet onmogelijk om tot één pasklaar antwoord (gegeven) te komen voor alle mogelijke situaties. Het benadrukken van een bepaald aspect of het analyseren van een deelprobleem is echter nog wel iets anders dan het ,divergeren der meningen"4).

\section{Par. 2 De informatieverstrekkende functie van waarderingsstelsels en calculatie methoden, accentverschuiving of iets nieuws?}

De belangstelling voor informatie en besluitvorming van de zijde van sociologen, psychologen, economen, computerdeskundigen en vele anderen is voortdurend groeiende. Ook de waarderingssystemen en calculatiemethoden ontkomen niet aan een beoordeling op hun informatieve kwaliteiten. De vraag is gerechtvaardigd of hier sprake is van een accentverschuiving of van een nieuwe benaderingswijze.

Verburg spreekt van een accentverschuiving als het gaat om de ontwikkeling van ,cost accounting" naar ,management accounting”. Volgens hem gaat het niet om principieel nieuwe inzichten en opvattingen met betrekking tot het verzamelen en verwerken van kostengegevens, maar om een aanpassing aan zich wijzigende omstandigheden ${ }^{5}$ ). Met deze zich wijzigende omstandigheden doelt Verburg dan met name op , de toenemende ingewikkeldheid van de interne en externe verhoudingen" en ,de ontwikkeling van het wiskundig en statistisch denken in de benadering van de bedrijfseconomische en bedrijfsorganisatorische vraagstukken"6).

3) Van Kampen, t.a.p. p. 157.

4) Van Kampen, p. 156.

5) P. Verburg, De betekenis van de kosteninformatie voor de besluitvorming, Leiden 1966, p. 5 .

6) Verburg, t.a.p. p. 4 en 5.

$m a b \quad b l z .470$ 
Ook Slot is van mening, dat er in de verschillende fasen in de ontwikkeling van de kostenberekening - de ontwikkeling van ,financial accounting” naar „management accounting" - sprake is van accentverschuivingen en niet zozeer van het ontwikkelen van nieuwe doelstellingen voor de kostenberekening ${ }^{7}$ ). Slot ziet de huidige fase dan ook als de fase van de ontwikkeling van één administratief systeem, waarin verschillende reeds bestaande kostenopstellingen zijn verenigd met als resultaat, ,dat daaruit ten behoeve van de meervoudige doelstelling van de calculatie ook een meervoudige informatie wordt verkregen"8).

Hoewel het construeren van een dergelijk administratief systeem geen eenvoudige zaak is en ongetwijfeld de informatieve mogelijkheden zal vergroten in vergelijking met ,enkelvoudige" administratieve systemen ben ik het toch niet geheel eens met de conclusie van Slot. Deze conclusie impliceert namelijk, dat de bestaande kostencalculatiemethoden en (waarderingsstelsels) in combinatie reeds iedere gewenste (kosten)informatie in zich bergen, die voor de besluitvorming in de onderneming van belang is en dat het alleen een kwestie is van efficiënt combineren in één systeem.

De in het verleden ontwikkelde waardetheorieën en calculatiemethoden zijn nimmer op strict formele wijze in verband gebracht met beslissingsmodellen. In de nederlandse bedrijfseconomische leerboeken staan de begrippen produktie en produktiefunktie centraal. De leer van de kwantitatieve verhoudingen en de leer van de kostprijs zijn de onderdelen, waarbij dit het duidelijkst naar voren komt. Zo omschrijft Limperg de kostprijs als volgt: „Onder de kostprijs van een goed is te verstaan de kwantitatieve voorstelling van het offer bij de ruil in het organische verband der voortbrenging"' $)$. Bij J. L. Meij treffen we de volgende omschrijving van de kosten aan: ,Bij de behandeling van deze kostencategorieën hebben we er reeds op gewezen, dat we alleen als kosten kunnen beschouwen de offers, die oorzakelijk met de produktie zijn verbonden en dus als noodzakelijk voor het verkrijgen van het verlangde produkt moeten worden beschouwd. Dit beginsel moet ons ook bij het verbijzonderen van de kosten leiden"10).

De kostenberekeningen dienen ook als grondslag voor de oplossing van het voorraadwaarderingsprobleem. Het waarderen van goederen tegen de integrale kostprijs berust op de mogelijkheid om het oorzakelijke verband tussen opgeofferde produktiemiddelen en produkten vast te stellen en op de veronderstelling, dat de waarde van het ene goed (produktiemiddel) overgaat op het andere goed (halffabrikaat of eindprodukt) ${ }^{1}{ }^{1}$ ).

Zodra men de besluitvorming in de onderneming centraal stelt en zich afvraagt welke informatie essentieel is voor de te nemen beslissingen hebben

7) R. Slot, De kostenberekening als hulpmiddel voor het bedrijfsbeheer, Management accounting, Maandblad voor Bedrijfsadministratie en -organisatie november/december 1967; enigszins gewijzigd overgenomen in R. Slot, Kostenvariabiliteit en variabele kostencalculatie, Leiden, 1968, A ppendix III, p. 260-282. Hier in laatstgenoemde uitgave geciteerd, p. 265.

8) t.a.p. p. 269.

9) Th. Limperg Jr., Bedrijfseconomie, Verzameld werk Deel 2, Leer van de kostprijs, Deventer 1968, p. 78.

10) J. L. Meij, Leerboek der Bedrijfseconomie, Deel I, 's Gravenhage 1960, p. 158.

11) Zie o.m. J. L. Meij, t.a.p. p. 31 e.v.

ma $b$ blz. 471 
we mijns inziens te maken met een geheel andere benadering van de bedrijfseconomische problematiek. Om over de betekenis van bepaalde gegevens als informatiebron voor de besluitvorming zinvolle uitspraken te kunnen doen, is het noodzakelijk uitspraken te doen over, in elk geval expliciet veronderstellingen te maken ten aanzien van de wijze waarop de besluitvorming tot stand komt. Men zal moeten komen tot het bouwen van beslissingsmodellen. De data die de informatie moeten verschaffen voor het nemen van goede beslissingen moeten afgestemd zijn op deze beslissingsmodellen. Dit is hetgeen nieuw is, althans nieuw zal moeten zijn aan "management accounting". In het bijschaven van bepaalde methoden en het combineren ervan in een nieuw ingenieus systeem schuilt het gevaar, dat men niet tot een optimale informatievoorziening komt. Pas wanneer de verdere ontwikkeling van administratieve systemen samengaat met of voorafgegaan is door een analyse van het besluitvormingsproces, zal blijken, in hoeverre de bestaande cijferopstellingen van essentieel belang zijn voor de besluitvorming, in hoeverre zij gewijzigd moeten worden, gecombineerd moeten worden of vervangen moeten worden door andere vormen van informatie ${ }^{12}$ ).

\section{Par. 3 De afstemming van de informatievoorziening op de besluitvorming}

In deze paragraaf zullen enkele essentiële punten met betrekking tot de afstemming van informatie en besluitvorming worden besproken. Aan welke eisen moet de informatie voldoen om als ,goede" informatie te kunnen worden gekwalificeerd. (Eigenlijk moeten we onderscheid maken tussen de gegevens, die de informatie bevatten en de informatie zelf. "Goede" gegevens zijn gegevens, die goede informatie kunnen verschaffen). De drie belangrijkste criteria, die men in de literatuur aantreft zijn:

A. de relevantie van de informatie,

B. de snelheid van de informatie,

C. de kosten van de informatie.

\section{A. De relevantie van de informatie}

De belangrijkste eis, die aan informatie moet worden gesteld is, dat de verstrekte informatie relevant moet zijn voor de beslisser en de te nemen beslissing. „Relevant data may be defined broadly as that data which will lead to an optimum decision"" 3 ). Men zou de relevantie van de informatie ook kunnen omschrijven als de mate waarin de resultaten worden verbeterd door het gebruik van deze informatie, de mate waarin de doelstellingen van de organisatie beter worden gerealiseerd. De relevantie van bepaalde informatie en dus ook de uitkomsten van calculatie- en waarderingsmethoden is afhankelijk van het doel waarvoor de informatie wordt aangewend. Om te beginnen kan hier

12) Hiermee wil niet beweerd worden, dat er nog geen enkele poging is ondernomen om het besluitvormingsproces te analyseren. Zie bv. H. A. Simon, Administrative Behavior, New York 1957 en P. Verburg t.a.p., in het bijzonder Hoofdstuk 3. De reeds bestaande kennis op dit terrein is echter nog zeer onvolledig en bovendien niet bij alle belanghebbenden bekend.

13) Charles T. Horngren, Choosing Accounting Practices for Reporting to Management, Contemporary Issues in Cost Accounting, Ed. Hector R. Anton en Peter A. Firmin, Boston 1966.

$m a b$ blz. 472 
gedacht worden aan het hoofddoel van de onderneming. Is het doel winstmaximalisatie (onder randvoorwaarden) of is het uitgangspunt omzetmaximalisatie (onder randvoorwaarden) of zijn de doeleinden gespecificeerd als streefniveau's om enkele mogelijkheden te noemen. Wat in het ene geval een relevant gegeven is, kan in een andere situatie volkomen irrelevant zijn en het is zelfs mogelijk, dat het zich baseren op deze gegevens aanleiding geeft tot beslissingen en conclusies, die strijdig zijn met de doelstellingen van de organisatie.

Een ander aspect van het doel waarvoor de informatie wordt aangewend is de aard van de te nemen beslissingen. De te nemen beslissingen in de onderneming en de daarvoor benodigde informatie kunnen op verschillende wijzen worden ingedeeld ${ }^{4}$ ). Indien de indeling geschiedt naar aanleiding van de vraag in hoeverre de informatieverstrekking en de besluitvorming geautomatiseerd kunnen worden kan een ander indelingscriterium worden verwacht dan wanneer men door middel van een empirische studie inzicht tracht te verkrijgen en systematiek tracht te brengen in het besluitvormingsproces ${ }^{14,15}$ ). Een bijkomende moeilijkheid bij het vergelijken van verschillende indelingen is het feit, dat de terminologie op dit punt niet eensluidend is bij de diverse auteurs. Aan de begrippen plannen, besturen, bijsturen, beheersen en regelen wordt een nogal uiteenlopende inhoud gegeven.

Globaal zou ik de volgende soorten informatie willen onderscheiden ${ }^{16}$ ):

a. Informatie, die nodig is om het beleid te formuleren, plannen op te stellen en uit te voeren.

b. Informatie, die nodig is voor de vorming van een oordeel over. de wijze waarop en de mate waarin door de diverse funktionarissen of groepen van funktionarissen respectievelijk door de onderneming als geheel activiteiten zijn (worden) verricht en in hoeverre de resultaten van deze activiteiten in overeenstemming zijn met de gestelde doeleinden en normen.

Verdere onderverdelingen van deze categorieën zijn mogelijk. Zo maakt Verburg onderscheid tussen de informatieverstrekking ten behoeve van de primaire besluitvorming en de informatieverstrekking ten behoeve van de overdracht en de realisering van de besluiten.

ad. a. Hieronder vallen ondermeer de gegevens over de dataconstellaties in het heden en de toekomst en over de alternatieven waaruit kan worden gekozen. Tot de beslissingen die worden gediend met deze informatie behoren bijvoorbeeld de keuze van de vestigingsplaats, de keuze van de produktietechniek, de beslissing inzake de aanschaf en vervanging van gebouwen en machines, de keuze van ,nieuwe" produkten, de keuze ten aanzien van nieuw te veroveren markten, de keuze van de organisatiestructuur, de keuze van de financiële structuur. Tot deze categorie van informatievoorziening be-

14) Zie A. Bosman, Systemen en Simulatie II, Maandblad voor Accountancy en Bedrijfshuishoudkunde, jrg. 42 (1968), p. 246. Bosman onderscheidt beslissingen in het besturingsvlak, beslissingen in het onderhandelingsvlak en beslissingen in het planningsvlak.

15) Simon onderscheidt (1) Score-card questions: „Am I doing well or badly?". (2) Attention directing questions: „What problems should I look into? (3) Problem solving questions: „of the several ways of doing the job, which is the best?". Zie Horngren, t.a.p. p. 5.

16) Zie o.a. Bosman, t.a.p. (Vgl. noot 14) Horngren, t.a.p. p. 5 e.v. en Verburg, t.a.p. p. 74 e.v. voor deze en andere indelingen en benaderingen. 
hoort ook de verkenning van de mogelijkheden en beperkingen waarmee de onderneming door haar omgeving wordt geconfronteerd. Door het signaleren van verschuivingen in de afzetmogelijkheden en veranderingen in de produktietechnologie wordt de leiding van de onderneming geattendeerd op nieuwe problemen, (attention directing questions) die om een oplossing vragen.

Vele van deze beleids- en planningsproblemen hebben een eenmalig karakter, zodat ook de voor de oplossing daarvan benodigde informatie slechts een keer wordt aangewend. Bijvoorbeeld: het signaleren van een nieuw type machine vestigt de aandacht op het probleem van de vervanging van reeds aanwezige machines. De gegevens die voor de beoordeling van de financiële aantrekkelijkheid van een eventuele vervanging worden verzameld hebben veelal slechts één aanwendingsmogelijkheid.

$a d b$. Uit de waarneming en rapportering van de prestaties (dit betreft dus de werkelijke gang van zaken) en een vergelijking van de werkelijkheid met de normen kunnen aanwijzingen worden verkregen omtrent een eventuele onbevredigende gang van zaken bij de uitvoering van de geplande activiteiten. De snelheid, waarmee gereageerd kan worden op een afwijking van de gestelde norm is onder meer afhankelijk van de wijze, waarop de norm is vastgesteld. Is de norm tot stand gekomen door een aggregatie over een bepaald tijdsinterval, dan is een vergelijking van realiteit en norm pas mogelijk aan het einde van dit interval. Deze vertraging en een aantal andere merendeels hiermee samenhangende omstandigheden (zoals het feit, dat door de aggregatie bij de normvaststelling de oorzaak van de afwijking niet eenvoudig en snel kan worden vastgesteld) is voor Bosman aanleiding om onderscheid te maken tussen beslissingen, waarbij onmiddellijk gereageerd wordt op een afwijking tussen norm en realiteit via een terugkoppeling (door hem beslissingen in het besturingsvlak genoemd) en beslissingen, waarbij een reactie pas een zekere tijd na het optreden van de afwijking plaatsvindt (door hem beslissingen in het onderhandelingsvlak genoemd $\left.{ }^{17}\right)$ ).

De geconstateerde afwijkingen kunnen na analyse in bepaalde gevallen relevante informatie verschaffen voor een verbeterde planning (in een volgende planperiode).

In vele gevallen is de beloning (geldelijke beloning, promotiekansen, gunst van superieuren en andere) van een functionaris afhankelijk van zijn prestaties. Uit dien hoofde kan de meting en beoordeling van de prestaties een gunstige preventieve invloed hebben op zijn instelling de gestelde normen na te leven.

$\mathrm{Bij}$ deze informatiecategorie (informatie nodig voor het vellen van een oordeel over de geleverde prestaties) kan ook gedacht worden aan de informatieverstrekking aan de aandeelhouders en andere belangstellenden in de gang van zaken in de onderneming als geheel.

Uiteraard zal bij een analyse van de beslissingen en de daarvoor benodigde informatie rekening gehouden moeten worden met de persoon van de beslisser en de plaats van deze persoon in de organisatie. De door hogere geledin-

17) Bosman t.a.p. p. 246.

$m a b$ blz. 474 
gen reeds genomen beslissingen leggen beperkingen op aan de keuzemogelijkheden voor de lagere geledingen. Het formuleren van de subdoelstellingen en het opstellen van de normen voor de lagere niveaus en/of onderdelen van de organisatie dient zodanig te geschieden, dat verwezenlijking bijdraagt tot het bereiken van de hoofddoelstelling(en).

\section{B. De snelheid van de informatie ${ }^{18}$ )}

Een belangrijk aspect bij de informatievoorziening is de snelheid, waarmee de noodzakelijke gegevens "kunnen worden geleverd en geanalyseerd. In principe relevante informatie kan volkomen irrelevant worden, als ze niet op het juiste moment beschikbaar komt. Wanneer bijvoorbeeld een afwijking tussen werkelijkheid en norm pas na verloop van tijd kan worden geconstateerd, kan op het moment van constateren de oorzaak al weer zijn opgeheven, zodat het ondernemen van enige actie geen zin meer heeft ${ }^{19}$ ).

Door het gebruik van computers zijn de mogelijkheden van snellere informatie toegenomen. Men dient echter wel te beseffen, dat niet iedere informatievoorziening zinvol door de computer kan worden uitgevoerd. Anderzijds bestaat echter ook de mogelijkheid van een teveel aan gegevens, waardoor de relevantie afneemt.

\section{De kosten van de informatie}

$\mathrm{Bij}$ de beantwoording van de vraag welke informatie gewenst is voor het nemen van goede beslissingen zal ook het kostenaspect in beschouwing moeten worden genomen. Steeds zal men zich moeten afvragen of de extra kosten van additionele informatie verantwoord zijn in verhouding tot de extra resultaten, als gevolg van de betere beslissing. De gevoeligheid van de oplossing van het betreffende probleem voor wijzigingen in de omvang van bepaalde variabelen (waaromtrent men extra informatie overweegt te verkrijgen) zal in belangrijke mate de extra opbrengst van de te verzamelen informatie bepalen. Het hebben van inzicht in de kosten van het verkrijgen van diverse soorten informatie wordt door Frielink gezien als een noodzakelijke voorwaarde voor een goede uitoefening van het accountantsberoep ${ }^{20}$ ).

\section{Par. 4 De betekenis van kostencalculatiemethoden en waarderingsstelsels als informatiebron voor de besluitvorming}

Wil er sprake zijn van enige betekenis van financiële gegevens voor de besluitvorming, dan zal de beslisser op enigerlei wijze moeten worden beínvloed, hetzij in gunstige, hetzij in ongunstige zin, door de uitkomsten van het gevolgde waarderingssysteem en de gehanteerde calculatiemethode(n). In het voorgaande is reeds opgemerkt, dat er mijns inziens nog onvoldoende inzicht bestaat in het besluitvormingsproces in de onderneming om een alleszins be-

18) Eventueel kan de snelheid van de informatie ook worden opgevat als een aspect van de relevantie.

19) Zie Bosman, t.a.p. p. 247.

20) A. B. Frielink, The adaptation of auditing te new techniques, Maandblad voor Accountancy en Bedrijfshuishoudkunde, jan/febr. 1968, p. 34. 
vredigend antwoord te geven op de vraag, wat de informatieve betekenis en invloed van deze gegevens is. Toch zijn er op grond van hetgeen in de voorgaande paragraaf is opgemerkt ten aanzien van ,goede" informatie wel een aantal - deels reeds geverifieerde - uitspraken te doen over deze problematiek.

Vele beslissingen, met name de beslissingen ten aanzien van de keuze uit alternatieve plannen, die in het heden worden genomen, zullen mede de gang van zaken in de toekomst bepalen ${ }^{2}$ ). Een nu gekozen alternatief kan pas in de toekomst worden uitgevoerd. De aantrekkelijkheid van een dergelijk alternatief zal dan ook bepaald worden door de verwachtingen ten aanzien van de voor de keuze relevante grootheden. In het kosten- en waarderingsvlak zijn dit verwachte prijzen, verwachte afzetmogelijkheden en verwachte kosten (uitgaven). Gegevens uit het verleden en het heden kunnen in dit verband alleen van betekenis zijn voorzover ze bijdragen tot het beter voorspellen van de toekomst en voorzover in het verleden genomen beslissingen nog doorwerken en allerlei beperkingen opleggen aan de keuzemogelijkheden in het heden en de te behalen resultaten in de toekomst.

Het kosten- en kostprijsbegrip, dat in het kader van de vervangingswaardeleer in de nederlandse bedrijfseconomische handboeken wordt gehanteerd is mijns inziens een in principe niet relevant gegeven als steunpunt voor bovengenoemde beslissingen. Afgezien van een aantal verschillen tussen de kostprijsbegrippen van diverse auteurs zijn er ook een aantal gemeenschappelijke uitgangspunten, waarvan de belangrijkste in dit verband zijn, dat geen rekening wordt gehouden in de kostprijs met verwachtingen en schattingen van prijzen en kosten en dat alleen die offers tot kosten worden gerekend, waarvan het verband met het produktieproces kan worden vastgesteld (denk aan de offers verbonden aan conjuncturele onderbezetting en de belastingen over rente van het eigen vermogen ${ }^{2}$ ). Met de onzekerheid, waarvan in de kostprijs is geabstraheerd, wordt de ondernemer (beslisser) geacht rekening te houden door het achteraf leggen van een intuitieve winstopslag op de kostprijs ter bepaling van de verkoopprijs.

Voorzover prijzen en kosten een rol spelen bij de beoordeling van alternatieven zal met de verwachtingen ten aanzien van deze variabelen, tot uitdrukking komende in (subjectieve) schattingen, en met de aan de schatting inhaerente onzekerheid in de calculaties ten behoeve van de besluitvorming expliciet rekening moeten worden gehouden ${ }^{23}$ ).

De in de bedrijfseconomie ontwikkelde waarderingsstelsels en waarderingsregels hebben betrekking op het waarderen van op een bepaald moment aanwezige voorraden goederen. Bij het waarderen van alternatieven gaat het echter om stromen, die zich over een of meerdere perioden uitstrekken. De voor

21) Verburg spreckt in dit verband van het afstemmen van de informatic op de draagwijdte van de beslissingen, Verburg, t.a.p. p. 156.

22) J. L. Meij basecrt zijn kostprijs op de voor het bedrijf meest geëigende produktiewijze en abstraheert dus volkomen van de mogelijke repercussies van beslissingen in het verleden voor het heden en voor de toekomst, J. L. Meij, t.a.p. p. 55; zie ook J. L. Bouma, Ondernemingsdoel en winst, een confrontatie van enkele theorieën van het ondernemingsgedrag (Lciden, 1966), p. 124

23) Vergelijk bijvoorbeeld, J. L. Bouma, Ondernemingsdoel en winst, p. 144 e.v. Bouma analyscert het verband tussen kostprijs, verkoopprijs en produktieomvang bij de veronderstelling, dat cr ten aanzien van de onvermijdelijke vervangingsoffers geen eenwardige schatting bestaat, maar dat er sprake is van een waarschijnlijkheidsverdeling.

$m a b$ blz. 476 
voorraden ontwikkelde regels zijn niet zonder meer van toepassing op stromen.

Een tweede kenmerk van beslissingen met betrekking tot de keuze uit alternatieven is, dat voorzover kosten en opbrengsten relevante factoren zijn voor deze keuze dit alleen geldt voorzover het de verschillen in kosten en opbrengsten tussen de beschouwde alternatieven betreft ${ }^{24}$ ). Men spreekt in dit verband ook wel van beslissingsafhankelijke kosten ${ }^{25}$ ). Het in de berekeningen opnemen van die kosten, die in de verschillende alternatieven hetzelfde zijn leidt niet direct tot foutieve calculaties, maar voor de keuze als zodanig zijn ze niet relevant. Uit een oogpunt van snelheid en kosten van de informatie kunnen ze ook veelal beter buiten beschouwing worden gelaten.

Of voor de keuze trouwens het verschil in kosten (en opbrengsten) relevante informatie is, staat niet zonder meer vast. Bij het gebruik van operational research technieken voor de oplossing van keuzeproblemen, blijken vaak heel andere faktoren zoals de technische coëfficienten en de in het model opgenomen beperkingen, bepalend te zijn voor de keuze ${ }^{26}$ ). Ook de volgende opmerking van Simon wijst in deze richting: ,If you allow me to determine the constraints, I don't care who selects the optimization criterion"2 7 ).

Indien het aantal beperkingen toeneemt - bijvoorbeeld bij beslissingen op lagere niveaus door de reeds genomen beslissingen op hogere niveaus - wordt het aantal alternatieven, waaruit kan worden gekozen kleiner. De beperkingen dwingen de keuze in een bepaalde richting en dit kan zelfs zover gaan, dat op het eerste gezicht relevante data uiteindelijk weinig of geen invloed hebben op de keuze. Met behulp van gevoeligheidsanalyses kan men enig inzicht verkrijgen in de bctekenis van bepaalde variabelen voor de kcuze. Veronderstel bijvoorbeeld dat er zeer uiteenlopende schattingen ten aanzien van het toekomstige prijsverloop bestaan, maar dat bij deze verschillende prijzen de keuze toch steeds ten gunste van hetzelfde projekt uitvalt. In die gevallen heeft het geen zin (voor deze keuze) zich moeite te getroosten om betere schattingen te verkrijgen van de toekomstige prijzen. De werkelijke hoogte, die de prijzen te zijner tijd zullen hebben, zijn natuurlijk wel van belang voor het vaststellen van het absolute resultaat van het gekozen alternatief. Een indeling van de kosten in beslissingsafhankelijke en beslissingsonafhankelijke kosten is in principe wel juist, maar zal gecombineerd moeten worden met een indeling naar de tijdsduur gedurende welke de beslissingsafhankelijke kosten worden beinvloed door een bepaalde beslissing.

Bij de beslissingen, die betrekking hebben op de beoordeling van de werkelijk geleverde prestaties zijn onder meer de volgende punten van belang.

$\mathrm{Bij}$ het vaststellen van de norm voor bepaalde prestaties dient ook aangegeven te worden in hoeverre afwijkingen van de gestelde norm bij de uitvoering als toevallige afwijkingen zijn te beschouwen en bij welke omvang van de

24) Horngren, t.a.p. p. 14.

25) Verburg, t.a.p. p. 156.

26) C. Churchill Neil and Metrew C. Stedry, Some Developments in Management Science and Information Systems with Respect to Measurement in Accounting, Research in Accounting Measurements, Eds. Robert K. Jaedicke, Yuji ljiri and Oswald Nielsen, (American Accounting Association 1966), p. 31.

27) H. A. Simon, On the concept of Organizational Goal, Administrative Science Quarterly, p. 9, nr. 1 (juni 1964), p. 6.

mal blz. 477 
afwijking verondersteld moet worden, dat er sprake is van een systematische afwijking, waarvan de oorzaak dient te worden opgespoord. Wanneer de waarneming van de uitvoering gekoppeld is aan een automatisch besturingsmodel, dat dus direct reageert op een geconstateerde (systematische) afwijking tussen norm en werkelijkheid, dan zal het constateren van de oorzaak van de afwijking snel moeten kunnen geschieden.

Ook zal van te voren een uitspraak gedaan moeten worden over de te nemen maatregelen, indien een bepaalde oorzaak van de afwijking is vastgesteld. Wil een dergelijke bijsturing goed functioneren, dan zal de norm niet door aggregatie van een groot aantal ,subnormen” of door aggregatie over een bepaald tijdsinterval tot stand moeten zijn gekomen, omdat de constatering van de afwijking en de analyse dan te veel tijd kosten. Mijns inziens komen hier eerder physieke hoeveelheden en technische coëfficienten in aanmerking als criterium voor de normvaststelling en de meting, dan kostengegevens in de vorm van kostprijzen, manuurtarieven, machineuurtarieven en dergelijke.

Wanneer de beoordeling van de prestaties met regelmatige tussenpozen plaats vindt omdat bijvoorbeeld de norm is ontstaan door aggregatie over een bepaalde tijdsperiode zal voor de analyse van de oorzaken van de afwijkingen toch terug gegaan moeten worden tot de elementaire onderdelen, waaruit de prestatie is samengesteld. Is de norm uitgedrukt in een bepaald budgetbedrag per periode, dan kan men weliswaar aan het einde van de periode het absolute verschil tussen werkelijkheid en budget vaststellen, maar dit zegt niets over de onderdelen waar en de omvang waarin positieve en negatieve verschillen zijn opgetreden.

In dit verband speelt ook een rol in hoeverre men de verantwoordelijke persoon voor de uitvoering speelruimte wenst te laten binnen het totale budget. Wanneer het acceptabel wordt geacht als afwijkingen naar boven worden gecompenseerd met afwijkingen naar beneden, zolang het geheel maar binnen de gestelde norm blijft, zal deze norm uitgedrukt moeten zijn in een eenheid, waarin ook alle onderdelen kunnen worden uitgedrukt; dit is veelal geld.

Wil men iemand verantwoordelijk stellen voor bepaalde kosten dan moet de persoon in kwestie ook deze kosten kunnen beinvloeden. Dit heeft geleid tot het principe van ,Responsibility Accounting”, hetgeen inhoudt, dat kosten en opbrengsten ten laste gebracht moeten worden van diegene, die verantwoordelijk is voor het ontstaan ervan. Hoewel iemand niet verantwoordelijk is voor het ontstaan van bepaalde kosten, zoals voor de kosten van dure apparatuur in een produktieafdeling over de aanschaf waarvan niet de produktiechef, maar anderen de beslissing hebben genomen, kan hij tot op zekere hoogte wel verantwoordelijk zijn voor een efficiënte en nuttige aanwending van deze produktiemiddelen. De vraag is echter, aan de hand van welke norm deze verantwoordelijkheid moet worden beoordeeld.

Het zorgen voor een evenwicht tussen de in- en uitgaande geldstromen, hetgeen een essentiële taak is voor de financiële planning, is een noodzakelijke voorwaarde om de doeleinden van de onderneming te kunnen verwezenlijken. Beslissingen in het heden genomen hebben ook financiële gevolgen voor 
de toekomst. Bij de financiële planning zal het ook gaan om verwachte inkomsten en uitgavenstromen (geen kosten en opbrengsten).

Voor de beoordeling van de activiteiten van de onderneming als geheel zou een vergelijking gemaakt moeten worden tussen de plannen en de bereikte resultaten. Het criterium, dat men moet aanleggen voor het al of niet geslaagd zijn van het gevoerde beleid hangt af van de doelstelling(en) van de onderneming. Voorzover (uitkeerbare) winst het criterium is, zal duidelijk omschreven moeten worden, wat men onder dit begrip verstaat en welke factoren bij de bepaling ervan in ogenschouw moeten worden genomen. De activiteiten moeten herleid worden tot resultaten. Hiervoor is een waarderingssysteem nodig $\left.{ }^{2}\right)$. Het uitvoeren van de geplande activiteiten strekt zich in het algemeen over meerdere perioden uit. Wanneer men tussentijds de stand van zaken wil bepalen en de resultaten wil berekenen, zullen de activiteiten omgerekend moeten worden in resultaten. De ontvangsten en uitgaven, die reeds plaats gevonden hebben en die nog plaats moeten vinden moeten aan de diverse perioden worden toegerekend. Van de op een bepaald moment aanwezige voorraden moet vastgesteld worden wat hun bijdrage is voor de verwezenlijking van de doeleinden. Hoe deze waardering moet plaats vinden (volgens welke regels en procedures) is afhankelijk van de nagestreefde doeleinden. Dat één bepaald systeem van waarderen als enig juiste voor alle situaties kan worden aangewezen is niet waarschijnlijk ${ }^{29}$ ). In het verleden zijn voortdurend pogingen ondernomen om een dergelijk volmaakt waarderingsprincipe te vinden. De benaderingswijze van de bedrijfseconomische problematiek van de informatieve waarde van verzamelde data brengt de discussie weer in de richting van het ontwikkelen van waarderingsprincipes en waarderingssystemen afhankelijk van het doel van de onderneming.

28) Zie ook J. L. Bouma, De Accountant, febr./maart 1968 , p. 503 e.v.

29) Vgl. R. Burgert t.a.p. 153-192. 